\title{
Letrōnica
}

\section{Poesia na Revista do Globo: duas fases, duas faces}

\section{Poetry in Revista do Globo magazine:}

two phases, two faces

Diego Grando'

Doutorando em Letras pela UFRGS. Mestre pela PUCRS, Licenciado em Letras pela UFRGS. Participou, durante os anos de 2007 e 2008, do projeto "A face literária da Revista do Globo. poesia, narrativa Therezinha Campos Moreira, como bolsista do CNPa

grando.diego@gmail.com.
RESUMO: A Revista do Globo (1929-1967) publicou, durante toda sua existência, uma expressiva quantidade de textos literários, nos mais variados gêneros. Analisar o material literário que figurou nas páginas do periódico pode oferecer uma visão complementar às visões já oferecidas pela História da Literatura, permitindo iluminar campos ainda obscuros ou confirmar teses já estabelecidas. Neste artigo, busca-se traçar um panorama da publicação de poesia na Revista do Globo, apresentando os números e os principais nomes publicados e levantando hipóteses sobre as mudanças quantitativas, estéticas e editoriais ao longo de sua história.

Palavras-chave: Revista do Globo; Rio Grande do Sul; Poesia.

ABSTRACT: Revista do Globo Magazine (1929-1967) published a significant amount of literary texts in a variety of genres during its existence. The analysis of the literary material featured on the pages of the periodical may offer a complementary perspective to the ones already provided by Literary History, which should allow to shed light upon fields requiring further research or to confirm established arguments. The aim of this paper is to provide an overview of poetry publication in Revista do Globo Magazine by presenting the issues as well as the main names published and raising hypotheses on quantitative, aesthetic and editorial changes throughout its history.

KEYworDS: Revista do Globo Magazine; Rio Grande do Sul; Poetry. 


\section{A Revista do Globo como objeto da História da Literatura}

m 5 de janeiro de 1929, a Editora Globo, casa editora criada pela Livraria do Globo, de Porto Alegre, lançava o primeiro número da Revista do Globo, que permaneceria em circulação, de forma ininterrupta, até 17 de fevereiro de 1967, contabilizando 943 fascículos (DELFOS, s.d.). Concebida estrategicamente para concentrar as peças publicitárias da Livraria do Globo, a Revista tornou-se a "vitrina dos produtos da Livraria do Globo e, mais tarde, da Editora Globo", sendo o principal veículo do grupo editorial a noticiar "lançamentos e reedições, entrevistas com autores nacionais e estrangeiros e todos os fatos que tivessem ligação com a vida literária” (DELFOS, s.d.).

O “Periódico de Cultura e Vida Social”, como definia-se em seu subtítulo, contava

geralmente com 80 ou 90 páginas, destinava-se ao público em geral, até mesmo às crianças; texto e imagem dividiam espaço, mas sempre com muita informação. Chegando aos sábados aos lares rio-grandenses, invariavelmente a cada quinze dias (de 10/01/31 a 28/02/31 foi semanal), durante 37 anos e dois meses, o periódico tornou-se importante veículo de cultura de massa, que divulgava, entre outros assuntos, a literatura e a arte em geral, ao lado de acontecimentos sociais e políticos, moda, humor, cinema e esportes. (DELFOS, s.d.)

Ao longo de sua história, a Revista teve, entre seus diretores mais célebres, as figuras de Erico Verissimo e Justino Martins. Sua importância, seja para a imprensa sul-rio-grandense e brasileira, seja para a História da Literatura, é múltipla, uma vez que um

destacado grupo de intelectuais e de artistas fizeram parte do seu corpo de redatores. Aí surgiram e se afirmaram muitas vocações que enriquecem a cultura nacional. A fisionomia da Revista, delineada ao longo de quase quatro décadas, identificou-se a tal ponto com seu contexto social que, de certa forma, pode-se dizer que a história da Revista do Globo se confunde com a própria história do Rio Grande do Sul nesse período. (DELFOS, s.d.)
Olhada retrospectivamente, portanto, a Revista pode servir a pesquisadores de diversas áreas do conhecimento como uma fonte histórica de altíssima relevância. Para o pesquisador de Literatura, em específico, o periódico oferece uma vasta gama de documentos propícios à análise e à interpretação, visto que os conteúdos literários (conto, crônica, poesia, fragmento de romance, resenha, crítica, ensaio etc.) estiveram sempre presentes em suas páginas, permitindo vislumbrar os gostos e expectativas do público leitor, bem como as etapas da formação do campo e do cânone literário sul-rio-grandense.

\section{Poesia na Revista do Globo}

Os mais de 1800 poemas que ocuparam as páginas da Revista do Globo distribuem-se de uma forma bastante diferente daquela sugerida pela média - caso caíssemos na tentação de calculá-la - de 48 poemas por ano, ou dois por volume. Há, isso sim, uma irregularidade gritante, que chega ao pico de 202 poemas no ano de 1931 e contrasta com um único poema durante todo o ano de 1952. Essa irregularidade não fala por si, uma vez que a trajetória da publicação de poesia em um veículo de comunicação impressa - cujo centro de interesse não é exclusivamente cultural, nem literário, nem poético - não obedece, e nem deveria obedecer, a leis estatísticas, mas sim a fatores sociais, culturais, editoriais e políticos de difícil identificação.

Uma tentativa de construir um panorama da poesia publicada na Revista do Globo não poderia, desse modo, levar em consideração apenas o paradoxalmente vasto microuniverso criado pelo próprio periódico, esquecendo de colocá-lo em relação com os momentos e nomes mais relevantes que hoje, com o distanciamento temporal que temos, fazem parte da história da poesia brasileira e, mais especificamente, sul-rio-grandense. Será esse, pois, o primeiro equívoco que tentarei evitar. 


\section{Números e fases}

Se não é possível tirar conclusões apenas a partir deles, ainda assim é importante ter em mente os números principais da presença da poesia na Revista do Globo:

Tabela 1 - Quantidade de poemas publicados por ano na Revista do Globo

\begin{tabular}{|c|c|}
\hline Ano & Poemas \\
1929 & 159 \\
1930 & 177 \\
1931 & 202 \\
1932 & 124 \\
1933 & 64 \\
1934 & 58 \\
1935 & 120 \\
1936 & 57 \\
1937 & 65 \\
1938 & 33 \\
1939 & 30 \\
1940 & 162 \\
1941 & 58 \\
1942 & 46 \\
1943 & 26 \\
1944 & 24 \\
1945 & 9 \\
1946 & 36 \\
1947 & 19 \\
1948 & 8 \\
Subtotal & $\mathbf{1 4 7 7}$ \\
\hline
\end{tabular}

Transpondo graficamente os dados da Tab. 1, uma trajetória irregular e descendente salta aos olhos, como se pode ver na Fig. 1:

Figura 1- Trajetória da poesia na Revista do Globo. 0 eixo vertical indica a quantidade de poemas publicados, e o eixo horizontal, o ano de publicação.

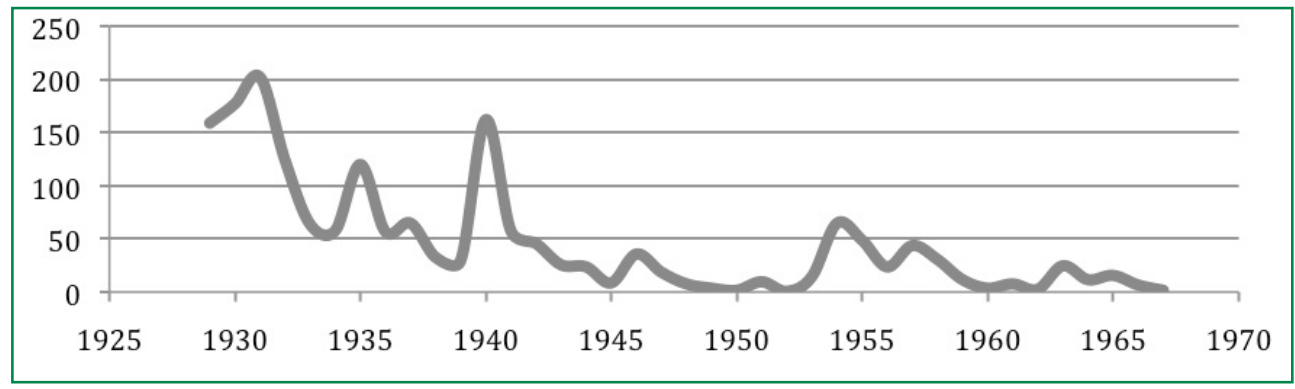

Uma primeira questão que se coloca diz respeito à maneira de avaliar esse declínio numérico: seria reflexo de um declínio do gênero como um todo (ou de seu público, ou dos poetas publicados e republicados, ou da própria revista), ou haveria outros fatores relacionados? Perda de interesse, seleção natural, mudanças editoriais, especialização, hermetismo, falta de mediação crítica, enfim, tantas hipóteses podem ser levantadas, assim a olho nu. O que, de imediato, não pode ser esquecido, é que os anos de existência da Revista foram marcados por expressivas transformações, tanto no campo político (a Revolução de 30 e toda a era Vargas, o governo JK, os primeiros anos de ditadura militar) quanto no estético (o modernismo brasileiro - ou do centro do país - quase do seu início até o surgimento do Concretismo). Consequentemente, os códigos sociais, culturais e artísticos acabaram por sofrer profundas modificações, o que influenciou os gostos e as sensibilidades. A poesia, nesse contexto e a seu modo, não poderia passar incólume. 
Sem muita matemática, mas com método, proponho a divisão do período em duas fases, que, apesar de não serem totalmente homogêneas (nem poderiam ser), assinalam uma mudança significativa na natureza da poesia publicada na Revista. A primeira fase, de 1929 a 1944, constitui um período de 16 anos e 1405 poemas. 0 ano de 1945, primeiro em que o número de poemas é inferior à dezena, inaugura a segunda fase, que se estende até 1967, totalizando 406 poemas em 23 anos. A relação inversa entre a duração da fase e o número de poemas publicados ajuda a reforçar a visão - como um retrato tirado de outro ângulo - de uma mudança de paradigma que, por sua vez, pode ser causa, ou consequência, de transformações tanto da política editorial da Revista, quanto do horizonte de expectativas de seu público.

\section{Primeira fase: $1929-1944$}

Não é o objetivo, aqui, fomentar a discussão sobre a validade da separação entre forma e conteúdo, ou de sua indissociabilidade, mas sim procurar desvendar, a partir desses dois eixos, a noção implícita de poesia que percorreu e pautou as páginas e o público da Revista. Porque, não se pode negar, sempre que há um poema, há um conceito de poesia a ele vinculado, seja esse conceito formulado verbalmente ou não, seja ele, ou não, consciente.

O ano de 1922 é considerado um divisor de águas na arte e, em específico, na literatura brasileira: trata-se do ano da Semana de Arte Moderna, marco inaugural do Modernismo no Brasil ${ }^{1}$. Tal movimento de renovação

\footnotetext{
Segundo Bosi (1994, p. 340), "a Semana foi, ao mesmo tempo, o ponto de encontro das várias tendências que desde a I Guerra se vinham firmando em São Paulo e no Rio, e a plataforma que permitiu a consolidação de grupos, a publicação de livros, revistas e manifestos, numa palavra, o seu desdobrarse em viva realidade cultural" (grifos no original).
}

vanguardista não caiu de forma imediata nas graças do público, ainda acos tumado ao beletrismo e à retórica de tendência parnasiana, bem encarnados na figura do Príncipe dos Poetas, Olavo Bilac. São ainda da década de 1920 o Manifesto Pau-Brasil (1924) e o Manifesto Antropófago (1928), de Oswald de Andrade e seus associados, bem como a transformação do grupo modernista Verde-Amarelo (1926) em Anta (1927), além da publicação de nada menos que Paulicéia Desvairada (1922), de Mário de Andrade, e PauBrasil (1925), de Oswald de Andrade (BOSI, 1994, p. 340-343). Década, enfim, de preparação de terreno, de choque e de conflito, que culminaria, em 1930, com as publicações de Libertinagem, primeiro livro propriamente moderno de Manuel Bandeira, e Alguma Poesia, estreia de Carlos Drummond de Andrade, obras de síntese que assinalam uma absorção da estética modernista à tradição poética brasileira, dos que viriam a ser dois dos mais importantes poetas do país.

A Revista do Globo surge no final dessa turbulenta década, e desde o princípio dá pistas de que Porto Alegre estava longe demais das capitais e de que as novidades de Rio e São Paulo demorariam um pouco a chegar, ao menos para o grande público. Em seu primeiro volume, de janeiro de 1929, publica-se um especial sobre o poeta simbolista gaúcho Eduardo Guimaraens, falecido no mês anterior, com direito a sete poemas de sua Divina Quimera, duas traduções suas (de Charles Baudelaire e Rabindranath Tagore) e uma versão fac-similada do manuscrito de "Aos Lustres", seu poema de estreia, escrito aos 16 anos. Diferente da versão que é hoje conhecida, o soneto vai aqui transcrito, com a grafia atualizada:

\section{Aos Lustres}

Pelos salões, à flor dos tetos elevados,

frágeis, imateriais, de um brilho transparente,

lustres!, pendentes no ar, enganadoramente,

ao mesmo tempo sois sonoros e calados. 
Quedo-me a olhar a luz que de todos os lados desce, fulge e, atenuando a irradiação silente,

torna vago e sutil o ambiente; e pelo ambiente

há sons de antigos sons sobre cristais gelados.

Contudo, quem pudera essa dor que transmuda

definir - que tortura e que estatua a face -,

quando a boca tem fala e é obrigada a estar muda?

Silêncio! E que em silêncio hinos a vós se formem,

pois profano rumor seria o que acordasse

as vibrações que em vós musicalmente dormem!

(REVISTA DO GLOBO, 1929, n. 1, p. 19)

Não se trata de um problema, longe disso, e a homenagem é mais do que merecida. Está dada, contudo, a tônica da primeira fase da poesia na Revista do Globo: preferência por artistas locais, muitos deles desconhecidos e/ou iniciantes, se não totalmente respeitosos - muitas vezes por falta de habilidade, e não por posicionamento estético-ideológico - às formas fixas, às regras de versificação e aos temas tradicionais, ao menos não preocupados em romper com isso, ou seja, em aderir ao processo de renovação modernista em marcha no centro do país. Eduardo Guimaraens, nesse contexto, representa o ponto máximo de realização desse conceito de poesia que domina a primeira fase: uma poesia de respeito formal, fiel aos modelos europeus, e de requinte vocabular. E, é necessário reconhecer, se Guimaraens é um dos expoentes do cânone sul-rio-grandense, ainda hoje ocupa uma posição secundária na história da poesia brasileira.

O universo poético desse período é extenso, porém, e não se resume a um Simbolismo tardio. Afinal, se ainda reina uma concepção tradicional e elitizante de poesia, que continua a ser o símbolo maior das "belas letras", do refinamento linguístico, do preciosismo técnico, em resumo, a quintessência da cultura letrada, é preciso que essa concepção seja constantemente reafirmada. Para isso, povoam as páginas da Revista poemas de clássicos brasileiros, tais como Machado de Assis, Casimiro de Abreu, Álvares de Azevedo, Castro Alves, Arthur Azevedo, Raimundo Corrêa, Olavo Bilac, Cruz e Souza, e estrangeiros, muitos deles no idioma original, como é o caso dos franceses Lamartine, Alfred de Musset, Jacques Delille, Paul Verlaine e Anna de Noailles. A língua e a cultura francesas, não esqueçamos, ainda reinam absoltas, nessa época, e representam um dos maiores indícios de requinte e sofisticação cultural.

Da grande massa de autores locais, há duas vertentes: uma regionalista, outra urbana. A separação, aqui, não é livre de confusão, já que aquilo que chamo de regionalista está tematicamente ligado ao universo gaúcho, seja o pampa, a serra ou qualquer outra cidade que mereça a homenagem de um poeta, ainda que bissexto, enquanto que a tendência urbana define-se negativamente: não é a que trata necessariamente de temas urbanos, mas a que pura e simplesmente não tematiza aquele universo campeiro. Na falta de melhor termo, fico com urbano. Destacam-se, do primeiro grupo, poetas e trovadores como Laurindo Ramos, Vargas Netto, Nogueira Leiria, Pedro Vergara, Dario Bittencourt e Pedro R. Wayne. Já o segundo grupo deixa ver o meio intelectual de Porto Alegre, onde circulam Álvaro Moreyra, Manoelito d'Ornellas, Mansueto Bernardi, Augusto Meyer, Zeferino Brasil, Felipe d'Oliveira, Mário Totta, Ernani Fornari, Alceu Wamosy, Athos Damasceno Ferreira, Damaso Rocha, Ovídio Chaves, entre outros, figuras que foram, sem dúvidas, relevantes no (e para o) contexto cultural sul-rio-grandense, mas que hoje não passam de nomes de ruas, escolas, bibliotecas e salas de teatro.

Mas há dois casos deste segundo grupo que merecem atenção especial, e, não à toa, são justamente os dois poetas com o maior número de poemas publicados. A diferença nos números, assim como em seus destinos literários, é flagrante. Pois, se há um nome que pode ter seu reconhecimento ligado à Revista do Globo, trata-se de Mario Quintana. Dos 174 poemas que ganharam 
as páginas da Revista (quase, ressalte-se, 10\% do total publicado), 159 apareceram nessa primeira fase, de 1929 a 1944. Já no segundo número, em 1929, o jovem poeta recebia uma página inteira para seu "Nocturno da Ruazinha Natal”, que ia assinado por “M. M. Quintana”, cujo segundo M., de Miranda, seria, já no soneto "Sentimentalismo", publicado no quinto volume da revista, apagado de seu nome artístico. Do poema que se conhece hoje por "Triste Encanto..." 2 , permanece apenas a estrofe inicial desta primeira versão:

\section{Sentimentalismo}

Triste encanto das tardes borralheiras, Que enchem de cinza o coração da gente! A tarde lembra um passarinho doente

A pipilar os pingos das goteiras...

Doçura de ficar, horas inteiras,

A recordar alguém que esteja ausente...

Revivem n'alma as ilusões primeiras,

As velhas impressões de antigamente...

E assim há de ser sempre, enquanto houver,

Para rezar-se, um nome de mulher!

Enquanto houver na terra, em cada furja,

Amor!... E enquanto houver separação...

Enquanto o espinho da saudade surja

Em meio às rosas da recordação...

(REVISTA DO GLOBO, 1929, n. 5, p. 7)

Mais poemas seus vão aparecendo, de vez em quando uma dedicatória a Dyonélio Machado, outra a Erico Verissimo, e então, em 22 de junho de 1940, um anúncio:

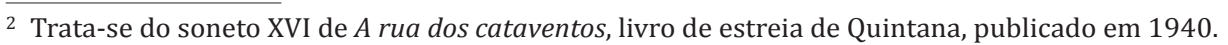

Como um presente aos seus leitores amantes da poesia, a "Revista do Globo" inicia hoje a publicação de "Espelho Mágico", o livro de quartetos inéditos de autoria do poeta Mario Quintana. Este é o seu segundo livro escrito, sendo, porém, o primeiro a ser divulgado, pois "A Rua dos Cataventos" - o prometido livro de sonetos de Mario Quintana, só deverá aparecer na primeira quinzena de julho.

"Espelho Mágico" é composto de 144 quartetos, mas Mario Quintana espera deixar 1.001 para a posteridade. (REVISTA DO GLOBO, 1940, n. 276, p. 24)

Era um golpe de sorte, ou de influência, ou ambos, que garantiria a Quintana, durante nove números sucessivos (do 276 ao 284), uma página inteira com 10 a 14 quartetos de Espelho Mágico, totalizando 110 dos 144 prometidos. Mais do que uma página por fascículo, de junho a dezembro, a estratégia folhetinesca de publicação de seu segundo-primeiro livro possibilitou ao poeta uma exposição enorme e jamais igualada - sequer aproximada - na história da Revista do Globo, além de um espaço nobre de publicidade para sua estreia em livro. Começa aí a nascer o mito Mario Quintana, que até hoje ocupa o posto de maior poeta do Rio Grande do Sul. Prova de que a estratégia foi acertada, e o sucesso, consequência natural.

O segundo lugar, com menos de um terço dos números de Quintana, mas nem por isso um caso menos interessante, é de Alzira Freitas. Com 43 poemas publicados, esta notável sonetista foi figura constante na Revista entre 1930 e 1937, mas seu nome, hoje, está longe de ser conhecido. Um poema, publicado em fevereiro de 1933, ajuda a ilustrar sua habilidade:

\section{Finados}

Ao cemitério fui à hora do poente,

pousadas tendo n'alma asas escuras,

a me acotovelar em meio a gente,

por ouvir, do cipreste, as queixas puras. 
Da tarde à claridade já morrente,

desenhando, no ambiente, iluminuras,

pus-me a vaguear, como um fantasma doente,

entre as filas das brancas sepulturas.

Por toda a parte, flores espalhadas..

um dilúvio caótico de rosas

em os braços das cruzes, enlaçadas.

E a sós, na sombra, eu exultei comigo...

pois que também um dia, mãos piedosas

cobrirão de papoulas meu jazigo.

(REVISTA DO GLOBO, 1933, n. 105, p. 27)

No período em que contribuiu com a revista, Alzira Freitas teve mais poemas publicados que Quintana (cujo salto numérico, como já exposto, deu-se em 1940). Apesar de seu nome ter sido saudado na época, não houve reconhecimento suficiente para garantir-lhe um futuro literário. Talvez por ser mulher num país ainda pouco acostumado a mulheres em posição de destaque (Cecília Meireles, até esta data, já havia publicado uma meia dúzia de livros de poemas, mas é exceção), talvez por simples capricho do destino, talvez por falta de qualidade, de influência ou mesmo de um mecenas, talvez por ter ficado presa demais aos valores poéticos que, ironicamente, ainda estavam em vigência. Valores, aliás, dos quais Quintana soube se valer para promover uma síntese com as novidades modernistas que, cada vez mais em voga no centro do país, começariam a ser compreendidas e a chegar ao Rio Grande do Sul pelas páginas da mesma Revista do Globo.

\section{Segunda fase: 1945-1967}

A segunda fase tem um antecedente em 1943: trata-se do volume de 9 de outubro, em que consta, acompanhando uma reportagem sobre Oswald de
Andrade, um fragmento de seu "Cântico dos Cânticos para Flauta e Violão"3, que vai aqui reproduzido:

\section{Cântico dos Cânticos para Flauta e Violão}

Não quero mais as moreninhas de Macedo.

Não quero mais as namoradas

do senhor poeta

Alberto d'Oliveira:

Quero você.

Não quero mais

Crucificadas em meus cabelos:

Quero você.

Não quero mais

a inglesa Helena,

Não quero mais

a irmã da Nena,

Não quero mais

Anabela,

Ana Bolena,

Quero você.

Toma conta do céu,

Toma conta da terra,

Toma conta do mar,

Toma conta de mim,

MARIA ANTONIETA D'ALKIMIM

(REVISTA DO GLOBO, 1943, n. 349, p. 18)

A provocação, a piada e a iconoclastia de Oswald de Andrade, mais de 20 anos depois da Semana de Arte Moderna, adentram o universo da Revista. E isso justamente na matéria assinada por Justino Martins, que,

3 Trata-se, em realidade, de um fragmento de "Canção e calendário", que integra o longo poema de Oswald de Andrade, "Cântico dos cânticos para flauta e violão", escrito em 1942. Na versão publicada em livro (ANDRADE, 1982), não há sinais de pontuação. 
entre constatações como "nada sabemos aqui no Rio Grande da maioria dos homens que escrevem em S. Paulo" (REVISTA DO GLOBO, 1943, n. 349, p. 18), tem o objetivo de apresentar e traçar um perfil do maior símbolo das vanguardas do país, rotulado por Martins de "o Rabelais brasileiro". Nada, como se percebe, de simplesmente deixar entrar a novidade que vem do centro do país. É preciso introduzir a mudança de paradigma, fazer paralelos, explicar seu valor, enfim, habituar o público da Revista à transformação dos padrões até então vigentes, ainda que, pelas próprias palavras do autor da reportagem, não sem uma boa dose de incompreensão: "eu, (sic) simplesmente me delicio com suas piadas e, muitas vezes, levo a sério sua literatura" (REVISTA DO GLOBO, 1943, n. 349, p. 18). Ou seja, o modernismo brasileiro chega como algo que pode, eventualmente, ser levado a sério.

Mas é mesmo a partir de 1945 que começam a aparecer poemas de Mário de Andrade, Manuel Bandeira, Carlos Drummond de Andrade, Vinícius de Moraes e João Cabral de Melo Neto, os nomes de peso da poesia brasileira moderna, o que assinala uma intensificação na relação com os acontecimentos poéticos do centro do país, um redirecionamento das antenas para o eixo da efervescência cultural brasileira. E é exatamente a partir desse momento que a poesia publicada na Revista do Globo chega ao ponto mais baixo de seu gráfico (cf. Fig. 1), e do qual não mais alçará voos numericamente tão altos: tem, esta segunda fase, uma média de 18 poemas por ano, o que contrasta fortemente com a média anual de 88 poemas da primeira fase.

Não figuremos, todavia, que a publicação desses autores significa uma mudança total de rota, nem uma adoção cega do modernismo. Afinal, os poetas contemporâneos do Brasil não andam sozinhos: somam-se a eles nomes como Shakespeare, Neruda, Mallarmé, Edgar Allan Poe, William Blake, Walt Whitman, Arthur Rimbaud, Ezra Pound, Rainer Maria Rilke e Emily Dickinson. Trata-se, pois, de um trabalho de tradução e de formação de um cânone universal bem mais largo que o da primeira fase, baseado quase que exclusivamente em franceses.

No quesito poesia traduzida, aliás, essa segunda fase foi testemunha da versatilidade de Manuel Bandeira, que assina traduções do inglês, do espanhol, do francês e do alemão, de poetas como Friedrich Hölderlin, Elizabeth Barret Browning, Paul Éluard, Francis Jammes, Gabriela Mistral e Juan Ramón Jiménez. Vale destacar, também, o poema "Dando adeus a um amigo", de Ezra Pound, em edição de agosto de 1955, numa tradução assinada por Augusto de Campos, à época com 24 anos, que viria a ser um dos grandes tradutores e teóricos da tradução poética do país, além de mentor do movimento concretista:

\section{Dando adeus a um amigo}

Azuis montanhas para o norte das muralhas,

Um branco rio serpeando entre elas;

Aqui devemos separar-nos

E seguir através mil milhas de relva morta.

0 pensamento como larga nuvem flutuante,

0 ocaso como o partir de velhas amizades

Que se inclinam sobre as mãos crispadas a distância

Nossos corcéis nitrindo um para o outro

Enquanto nós partimos.

(REVISTA DO GLOBO, 1955, n. 644, p. 17)

O poema é acompanhado por uma foto de Pound e uma apresentação do autor, num misto de empenho didático, argumento de autoridade e desejo de polêmica:

EZRA POUND, grande representante dos "imagistas", famosa escola literária dos Estados Unidos, [...] é considerado o maior poeta americano atual. Colaborador dos fascistas durante a última guerra, Pound foi julgado mas recolhido a um asilo, por Loucura. Grande teórico da poesia, ele atualmente dedica-se a traduções. (REVISTA DO GLOBO, 1955, n. 644, p. 17) 
Quem perde espaço com nesse afunilamento são os poetas locais. Não desaparecem de todo, logicamente: ainda há Mario Quintana, cujo prestígio não para (nem parará) de aumentar. Em 1963, em coluna assinada por Walter Spalding, publica-se um perfil (de duas páginas) de Athos Damasceno Ferreira, poeta e tradutor da Editora Globo, acompanhado por um desenho de João Fahrion, ilustrador da Revista, e por 17 poemas. Na verdade, são quadras que compõem um conjunto intitulado "Baile de Máscaras", entre os quais estão o próprio Quintana, Augusto Meyer, Erico Verissimo, Theodomiro Tostes, Moysés Vellinho, Reinaldo Moura, Viana Moog e Henrique Bertaso. Três exemplares da série, espécie de coluna social versificada da intelectualidade sul-rio-grandense:

\section{Erico Veríssimo}

Reside, entre paredes, toda gente,

- em casa ilustre ou cochicholo sujo -

mas este mora, inteligentemente,

dentro de um caramujo...

\section{Mario Quintana}

Não lhe receitem cataplasmas,

nem lhe deem solução aos problemas bizarros...

deixem-no a sós com os seus fantasmas,

deixem-no a sós com os seus cigarros...

\section{Henrique Bertaso}

Na geral opinião dos editados,

ei-lo: - é uma fina, uma perfeita joia...

E para tratar bem esses ventres chupados,

paga os direitos autorais e a... boia...

(REVISTA DO GLOBO, 1963, n. 849, p. 24-25)

Também há lugar, mesmo que reduzido, para os poetas gaúchos da nova geração, como Lara de Lemos (dois poemas), Carlos Nejar (dois poemas) e
Armindo Trevisan (um poema). Já se sabe, contudo, desde a primeira fase, que os poetas locais são a areia mais grossa, bruta e abundante e, portanto, com o entrançar dos fios da peneira, são os primeiros a ficar de fora. É o fim dos iniciantes e inexperientes, dos poetas bissextos e de ocasião, dos fazedores de versinhos: quando chega a poesia que pode muitas vezes ser levada a sério, aí mesmo é que ela passa, paradoxalmente, a ser levada a sério.

Mas levada a sério por quem? Afinal, a diminuição na publicação de poesia pode refletir tanto uma política editorial da revista - de definir, a partir de então, a qualidade, e não a quantidade, como critério - quanto o gosto de um público que, ainda atendo-se a modelos e valores poéticos mais próximos aos da primeira fase, desinteressa-se progressivamente pela poesia, dialeticamente obrigando a Revista a publicar cada vez menos.

Ou, talvez, a estratégia de levar a sério o que nem sempre pode ser levado a sério (Justino Martins tinha lá sua dose de razão) acaba sendo a contradição insolúvel da arte moderna, ou ao menos uma fração dela: quanto mais conta com a incompreensão como valor estético, mais consegue ser de fato incompreendida e, com isso, afastar-se dos leitores. Assim, e não é nenhuma novidade, nem exclusividade da poesia brasileira, a poesia torna-se produto de nicho, código para iniciados, arte para especialistas, e a Revista do Globo nada mais faz do que flagrar, em sua história, esse processo. A poesia, parece, quanto mais tenta falar a língua do povo, menos fala ao povo.

Derivaria daí a necessidade da mediação crítica, do desvendamento de qualidades pouco visíveis a olho nu pelo leitor habituado ao paradigma anterior - tornado subitamente em um leitor leigo no novo paradigma -, isto é, da compreensão da complexidade de um discurso travestido de simplicidade. E assim, torna-se moeda cada vez mais corrente a presença da poesia acompanhada ou dentro de comentários críticos.

Exemplo disso está no fascículo de 22 de julho de 1950, em que a seção "Correio Literário do Rio" apresenta o artigo "Lição de Poesia de Mestre 
Bandeira"4. Ali é feita uma análise de duas versões do poema "Camelots", de Manuel Bandeira, uma delas pertencendo ao volume Libertinagem, e a outra, à edição das Poesias Completas, Tal cotejo serviria para ilustrar que, "embora tais modificações fossem mínimas, já [me] pareceram bem expressivas do cuidado com que Bandeira trabalha os próprios versos, no sentido de melhorá-los, até atingirem uma forma que satisfaça seu agudo senso artístico" (REVISTA DO GLOBO, 1950, n. 513, p. 21). As duas versões foram sobrepostas, ficando entre parênteses "as expressões e os sinais de pontuação cortados na versão definitiva, e em itálico as palavras não existentes na primitiva" (REVISTA DO GLOBO, 1950, n. 513, p. 21):

Abençoado seja o camelot (que vende) dos brinquedos de tostão.

0 que vende balõezinhos de cor

0 macaquinho que trepa (pelo) no coqueiro (acima)

0 cachorrinho que bate com o rabo

Os homenzinhos que jogam box

A perereca verde que de repente dá um pulo (chi) que engraçado(!)

$\mathrm{E}$ as canetinhas tinteiro que jamais escreverão coisa alguma(!)

Alegria das calçadas(...)

Uns falam pelos cotovelos:

- "O cavalheiro chega em casa e diz: Meu filho,

vai buscar um pedaço de banana para eu acender o

charuto. Naturalmente o menino pensará: Papai

está malu..."

Outros, coitados, têm a língua atada.

Todos(,) porém(,) sabem mexer nos cordéis com (aquele) tino ingênuo de demiurgos de inutilidades.

E ensinam no tumulto das ruas os mitos heroicos da meninice(.)...

E dão aos homens que passam preocupados ou tristes

uma lição de infância.

(REVISTA DO GLOBO, 1950, n. 513, p. 21 e 67)

${ }^{4}$ Estranhamente, o artigo, escrito na primeira pessoa do singular, não é assinado.
A comparação das duas versões serve, além disso, para "demonstrar como se enganam os que falam da 'facilidade' da poesia moderna, os que supõem que os poetas de hoje são indiferentes ao ritmo e à harmonia do verso" (REVISTA DO GLOBO, 1950, n. 513, p. 21). Finalidade, portanto, didática, que se embasa nas diferenças de percepção da crítica e do grande público:

É já um lugar comum dizer-se que a chamada poesia moderna, por isso mesmo que se despojou de todos os elementos artificiais, como a rima e métrica, precisa, mais do que qualquer outra, apresentar perfeito ajustamento entre a ideia e a forma, devendo ter também, de certo modo, a sua métrica. $A$ maioria dos leitores, porém, não pensa assim. Daí por que será sempre oportuno demonstrar como os problemas de forma preocupam os maiorais de nossa Poesia de hoje. (grifo meu) (REVISTA DO GLOBO, 1950, n. 513, p. 21)

Caberia ao leitor da Revista do Globo, então, reeducar-se e adaptar-se aos novos parâmetros da poesia. Ou deixá-la, de uma vez por todas, apenas para os iniciados.

\section{A questão do lugar: uma conclusão}

Também se pode saber - e muito - sobre a poesia na Revista do Globo sem mesmo lê-la, apenas levando em conta o lugar que lhe era destinado. E eis que novamente, de uma fase a outra, descobre-se um contraste fortíssimo. Com base no que já se viu, em termos de quantidade e de alinhamento estético, confirma-se uma lógica que se poderia supor: quanto mais poemas, mais espaços variados eles ocuparão; e quanto menos, menos.

Assim é que, durante a primeira fase, aparece poesia por todos os cantos: nas colunas sociais, nas participações de casamentos, nascimentos e aniversários de quinze anos, nos pés de páginas, nas seções femininas e infantis, na propaganda e, até mesmo, na literatura. Os títulos das seções, 
aliás, em que a presença de poemas era frequente ajudam a dar uma dimensão aproximada dos respingos da poesia. São elas: Sociedade, Vida Literária, Página dos Novos, Tua..., Poesia, Colaboração Feminina, Azulejos, De Bom Humor, Escola de Corte, Pathe-Baby, Guri!, Colaborações, A Hora da Saudade, Sociais, A Sua Página, Um Poeta por Quinzena, Atualidade Literária e Espírito do Tempo.

Entende-se, desse modo, como circulou tanta poesia nessa primeira fase: pelo simples fato de ela, muitas vezes, não ser o foco, e sim o adereço, o arremate, o anexo. Mais um atestado de que a poesia não era feita exclusivamente por poetas, nem exclusivamente lida por entendidos, circulando - e deixando-se circular - livremente entre notícias, atualidades, imagens e pessoas comuns. Há uma ingenuidade autêntica e muito singela nisso.

Mas a guinada dos anos 1940, a mudança de orientação em marcha - da revista ou da própria poesia brasileira? - e, sobretudo, a recessão de poemas também influem na questão do lugar. Agora, na segunda fase, a regra vira exceção, e é cada vez mais difícil encontrar poesia fora do lugar milimetricamente dedicado a ela, que corresponde a uma pequena fração da seção literária, cujo nome muda com o decorrer dos anos. Assim, a poesia passa da seção Escritores e Livros para Literatura e Arte, depois Literatura, novamente Escritores e Livros, e, finalmente, Literatura Hoje. Direciona-se, portanto, quase que inteiramente ao público interessado por literatura, cristalizando-se em seu nicho e fechando-se em torno da própria circunferência.

Não há mais espaço, então, para um elogio à nova Miss Universo, para uma saudação à Festa da Uva ou para uma propaganda da Casa Brasileira. Versos são para os que sabem fazê-los, para os leitores que sabem lê-los, em terreno cada vez mais privado, e em proporção - de poemas e leitores cada vez menor: eis um possível retrato da poesia brasileiro de boa parte do século XX que a Revista do Globo, sob os olhos de hoje, nos permite flagrar.

\section{Referências}

ANDRADE, Oswald. Cadernos de poesia do aluno Oswald (Poesias reunidas). São Paulo: Círculo do Livro, 1982.

BOSI, Alfredo. História concisa da Literatura Brasileira. São Paulo: Cultrix, 1994.

DELFOS - ESPAÇO DE DOCUMENTAÇ̃̃O E MEMÓRIA CULTURAL. [s.d.] Revista do Globo. Disponível em: <http://www.pucrs.br/delfos/?p=globo>. Acesso em: 10 mar. 2015.

QUINTANA, Mario. A rua dos cataventos. São Paulo: Globo, 2005.

REVISTA DO GLOBO. In: MOREIRA, Alice Therezinha Campos et al. Revista do Globo (1929-1967): catálogo e texto. Porto Alegre: PUCRS/Laboratório de Acervos Digitais, 2003. 15 CD-ROMS.

Recebido em 10/04/2015

Aceito em 06/08/2015 